\title{
Video Article \\ Interview with Eric R. Kandel: From Memory, Free Will, and the Problem with Freud to Fortunate Decisions
}

\author{
Eric R. Kandel, M.D. ${ }^{1,2}$ \\ ${ }^{1}$ Howard Hughes Medical Institute Research Laboratories \\ ${ }^{2}$ Center for Neurobiology and Behavior, Columbia University \\ URL: https://www.jove.com/video/762 \\ DOI: doi:10.3791/762
}

Keywords: Neuroscience, Issue 15, Nobel Prize, Aplysia, learning, memory, neurogenesis, hippocampus

Date Published: 4/24/2008

Citation: Kandel, M.D., E.R. Interview with Eric R. Kandel: From Memory, Free Will, and the Problem with Freud to Fortunate Decisions. J. Vis. Exp. (15), e762, doi:10.3791/762 (2008).

\section{Abstract}

Eric R. Kandel shared the Nobel Prize for Physiology or Medicine with Arvid Carlsson and Paul Greengard in 2000 for their discoveries concerning signal transduction in the nervous system. Eric Kandel was rewarded for his discoveries of molecular mechanisms underlying learning and memory. $\mathrm{He}$ is a Howard Hughes Medical Institute Senior Investigator at Columbia Universities Center for Neurobiology and Behavior.

In this interview given at Hertie Foundation's Neuroforum 2008 on April 18, 2008 in Frankfurt, Germany, Nobel Prize Laureate Eric R. Kandel takes us on an enlighting journey ranging from memory, free will, the problem with Freud, to scientific challenges and the rise of European science. Starting with short- and long-term memory basics, underlying molecular mechanisms, and events affecting the formation of long-term memory, Eric Kandel then shares his thoughts on the issue of free will and makes a strong case for its existence. In addition to his outstanding scientific career, Eric Kandel developed an interest in business and today serves as scientific advisor at Memory Pharmaceuticals. Eric Kandel then talks about the use and abuse of drugs in children and the merging of scientific disciplines. In one of the most intriguing parts of the interview, Kandel shares his thoughts on Freud, Freud's mistakes, and the unique situation that the generations following Freud did not develop Freud's work further. The interview then turns to more scientific aspects and Eric Kandel talks about his confidence and courage during the initial phases of his scientific career, studying learning and memory, and employing a strictly reductionistic approach, best characterized by his simple model organism Aplysia. Eric Kandel then describes one of the most challenging phases in his scientific career when adult neurogenesis was discovered in the hippocampus, a structure so integral to Kandel's work. The final parts of the interview cover today's absence of epic battles and controversies and the rise of European science.

\section{Video Link}

The video component of this article can be found at https://www.jove.com/video/762/

\section{Disclosures}

The authors have nothing to disclose. 